\title{
Parasitic infection mimicking acute appendicitis in an adult male-A rare case
}

\begin{abstract}
The most common helminthic infection in gastrointestinal tract (GIT) is considered to be Enterobius Vermicularis and when it affects appendix it produces symptoms of acute appendicitis. Its association with acute appendicitis varies from $0.2 \%$ to $41.8 \%$, most predominantly affecting children and rare in adults. We present a case of 22 year old male clinically diagnosed as acute appendicitis but pathological examination revealed Enterobius Vermicularis infection in appendix which is an infrequent finding. The intestinal parasitic infection may mimic acute appendicitis clinically but careful examination and evaluation of symptoms such as pruritis ani or eosinophilia on blood examination may be present.
\end{abstract}

Keywords: acute appendicitis, enterobius vermicularis, adult, rare, histopathology
Volume 4 Issue 5 - 2017

\author{
Varsha Bhatia,' Ashish Jawarkar, ${ }^{2}$ Varun \\ Gohil, $^{3}$ Darshana Patel ${ }^{2}$ \\ 'Associate Professor, Dept of Pathology, PIMSR, Gujarat \\ ${ }^{2}$ Assistant Professor, Dept of Pathology, PIMSR, Gujarat \\ ${ }^{3}$ Tutor, Dept of Pathology, PIMSR, Gujarat
}

Correspondence: Varsha Bhatia, Dept of Pathology, PIMSR 8/A, Jaya Apts, Cama Lane, Kirol Road, Ghatkopar west. Mumbai-400086, India, Tel 986757/769,

Emaildrvarshabhatia@gmail.com

Received: April 02, 2017| Published: June 08, 2017

\section{Introduction}

The most common helminthic infection occurring worldwide is considered to be Enterobius Vermicularis commonly known as pinworm or thread worm mainly in GIT. ${ }^{1,2}$ The incidence of Enterobius Vermicularis infection is predominantly seen in children which is around $4 \%$ to $28 \%$ and is rarely seen in adults. ${ }^{3,4}$ The most common route of infection is through feco-oral route. Enterobius Vermicularis infection is generally asymptomatic, if it infects appendix it may mimic acute appendicitis without histological evidence of acute inflammation. ${ }^{5,6}$ The pathological diagnosis of Enterobius Vermicularis in appendix is an infrequent finding and is mainly associated with chronic inflammatory infiltrate \& eosinophils in the mucosa without invasion of mucosa by the parasite. ${ }^{7}$ We report a case of 22year old young adult male with right iliac fossa tenderness who underwent appendicectomy and pathology revealed Enterobius Vermicularis.

\section{Case presentation}

A 22year old male patient came to the casualty department with pain in abdomen. On physical examination there was right iliac fossa tenderness. A laboratory investigation revealed a normal Complete Blood Count (CBC). Serum immunoglobulins levels were not done in this patient as clinicians did not suspect parasitic infection as a cause of acute appendicitis. Ultrasonography was performed and did not show inflammation of appendix or any other abdominal organ. Clinical diagnosis of acute appendicitis with unkown etiology was made and patient underwent open appendicectomy. The specimen was sent for histopathological examination to know the exact cause of appendicitis. On gross examination appendix appeared normal with presence of fecolith. Microscopic examination revealed mucosa with inflammatory infiltrate predominantly comprising of eosinophils which is most commonly seen in parasitic infection and lumen showed parasite of Enterobius Vermicularis (Figure 1 \& Figure 2). The rest of the layer submucosa, muscle layer and serosa appeared normal and showed no evidence of neutrophilic infiltrate or congested blood vessels which is usually is seen in acute appendicitis without parasitic infection (Figure 3 ). The diagnosis of acute appendicitis secondary to
Enterobius Vermicularis infection was given. Post operatively a dose of mebendazole $100 \mathrm{mg}$ was given and patient is being followed up.

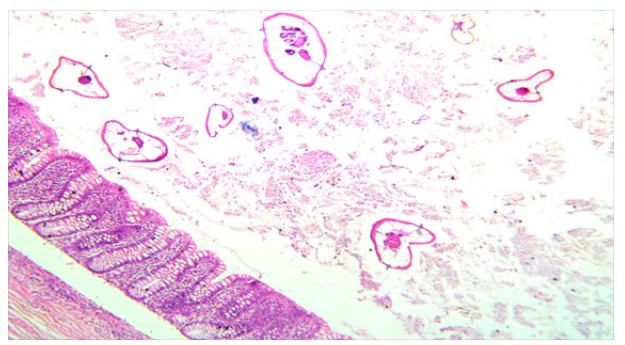

Figure I Microscopic photo showing mucosa of appendix with lumen showing multiple enterobious vermicularis parasite $(\mathrm{HE}, \mathrm{XIO})$.

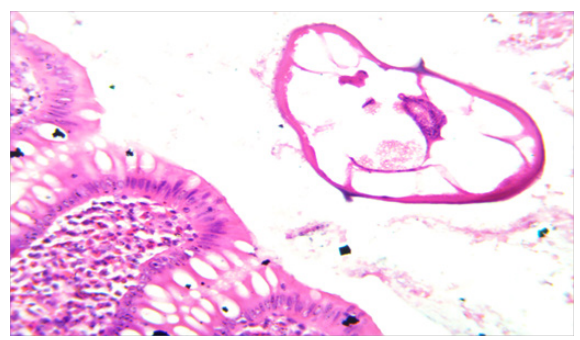

Figure 2 Microscopic photo showing mucosa of appendix with eosinophils in lamina propria and enterobious vermicularis parasite in lumen (HE, X40).

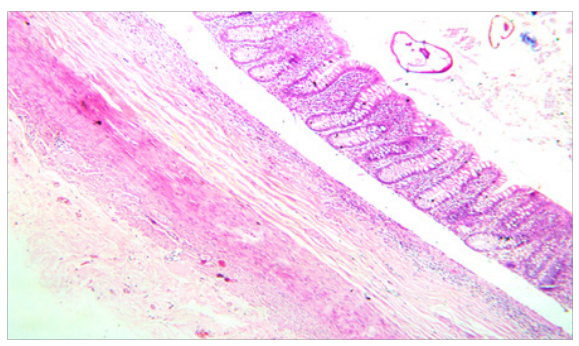

Figure 3 Microscopic photo showing the rest of the layers of appendix submucosa, muscle layer and serosa without inflammatory infiltrate $(\mathrm{HE}, \mathrm{XIO})$. 


\section{Discussion}

The most innocent looking organ in human body is appendix. It is situated below ileocecal valve in the caecum and has tubular structure with narrow lumen. Acute appendicitis is the most common surgical emergency and is treated by appendicectomy. ${ }^{8}$ The common and most important causes of acute appendicitis is fecolith, stasis of fecal matter and hyperplasia of lymphoid tissue but intestinal parasite causing acute appendicitis is a quite a rare event. ${ }^{9}$ There are only $1 \%$ cases of appendicitis which are predominantly infected by Enterobius Vermicularis. ${ }^{10}$ It is most commonly seen in children but rarely seen in adults, our patient was an adult male. It is generally asymptomatic but patient can present with pruritis, lethargy and generalised weakness. It may give rise to abdominal or appendicular colic thus mimicking symptoms of acute appendicitis resulting in appendicectomy, this was the clinical presentation seen in our patient. Enterobius Vermicularis is seen in $0.6 \%$ to $3.8 \%$ appendicectomy specimens. ${ }^{11}$ The association of pinworm and appendicitis is known since early $20^{\text {th }}$ century but its role in producing symptoms of acute appendicitis is still controversial, this parasite is most commonly seen in histologically normal looking appendix and at the same time can give rise to symptoms of acute appendicitis. ${ }^{12}$ The appendix removed in our patient showed Enterobius Vermicularis in the lumen with eosinophils in the mucosa and no evidence of neutrophilic infiltrate. In the literature very few studies have found pinworm associated with acute and chronic inflammation ranging from $13 \%$ to $37 \% .^{13}$ Appendicectomy is the treatment of choice of acute appendicitis but if it is caused by Enterobius Vermicularis infection then the treatment of choice is antihelminthic drug such as albedazole or mebendazole without the need of surgery. Thus detailed clinical history and patient with repeated examination and a good clinical knowledge of treating physician can avoid unnecessary surgeries.

\section{Conclusion}

Acute appendicitis due to Enterobius Vermicularis infection is rarely seen in adults. In both developing and developed countries the continuing challenge of diagnosis pinworm infestation remains a considerable problem. With modern management mortality is low but morbidity still exists. Without high index of suspicion preoperative diagnosis of pinworm infection is almost difficult. Thus all appendicectomy specimens should be subjected to histopathological examination to avoid missing diagnosis and the patient along with its family members should be treated with antihelminthics postoperatively because the surgery will eliminate the complication and the not the cause of intestinal disease.

\section{Acknowledgements}

None.

\section{Conflict of interest}

The author declares no conflict of interest.

\section{References}

1. Kumar U, Jha NK, Sinha DK. Acute Appendicitis due to Enterobius Vermicularis in a middle aged adult, rare finding- a case report. Journal of Dental and Medical Sciences. 2013;6(1):49-50.

2. Goldman DA, Wilson CM. Pinworm infestations: Primary pediatric care. 3rd ed. St Louis: Mosby: Hoekelman RA; 19971519.

3. Henley M, Sears JR. Pinworms: a persistent paediatric problem. MCN Am J Matern Child Nurs. 1985;10:111-113.

4. Liu LX, Weller PF. Intestinal nematodes. In Harrison's principles of internal medicine. 13th ed. Isselbacher KJ, et al. editors. New York, USA: McGraw-Hill; 1994. 919 p.

5. Yildirim S, Nursal TZ, Tarim A, et al. Rare cause of acute appendicitis: parasitic infection. Scand J Infect Dis. 2005;37(10):757-759.

6. Panidis S, Paramythiotis D, Panagiotou D, et al. Acute appendicitis secondary to Enterobius vermicularis infection in a middle-aged man: a case report. Journal of Medical Case Reports. 2011;5:559.

7. Surmont I, Liu LX. Enteritis, eosinophilia and enterovius vermicularis Lancet. 1995;346:1167.

8. Burkitt DP. The aetiology of appendicitis. Br J Surg. 1971;58(9):695-699.

9. Yabanoğlu H, Aytaç HÖ, Türk E, et al. Parasitic Infections of Appendix. Turkiye Parazitol Derg. 2014;38(1):12-26.

10. Gupta SC, Gupta AK, Keswani NK, et al. Pathology of tropical appendicitis. J Clin Pathol. 1989;42(11):1169-1172.

11. Aydin O. Incidental parasitic infestations in surgically removed appendices: a retrospective analysis. Diagn Pathol. 2007;2:16.

12. Akbulut S, Tas M, Sogutcu N, et al. Unusual histopathological findings in appendicectomy specimens: A retrospective analysis and literature review. World J Gastroenterol. 2011;17(15):1961-1970.

13. Dahlstrom JE, Macarthur EB. Enterobius vermicularis: a possible cause of symptoms resembling appendicitis. Aust N Z J Surg. 1994;64:692-694. 